\title{
Thermal Evaluation of Railway Transformer Used in Autotransformer Feeding Systems
}

DOI:

10.1109/energycon.2018.8398739

\section{Document Version}

Accepted author manuscript

Link to publication record in Manchester Research Explorer

\section{Citation for published version (APA):}

Han, M., Hill, J., Wang, Z., \& Crossley, P. (2018). Thermal Evaluation of Railway Transformer Used in Autotransformer Feeding Systems. In 5th IEEE International Energy Conference https://doi.org/10.1109/energycon.2018.8398739

\section{Published in:}

5th IEEE International Energy Conference

\section{Citing this paper}

Please note that where the full-text provided on Manchester Research Explorer is the Author Accepted Manuscript or Proof version this may differ from the final Published version. If citing, it is advised that you check and use the publisher's definitive version.

\section{General rights}

Copyright and moral rights for the publications made accessible in the Research Explorer are retained by the authors and/or other copyright owners and it is a condition of accessing publications that users recognise and abide by the legal requirements associated with these rights.

\section{Takedown policy}

If you believe that this document breaches copyright please refer to the University of Manchester's Takedown Procedures [http://man.ac.uk/04Y6Bo] or contact uml.scholarlycommunications@manchester.ac.uk providing relevant details, so we can investigate your claim.

\section{OPEN ACCESS}




\title{
Thermal Evaluation of Railway Transformer Used in Autotransformer Feeding Systems
}

\author{
Mingyu Han, James Hill, Zhongdong Wang, Peter Crossley \\ School of Electrical and Electronic Engineering \\ The University of Manchester \\ United Kingdom \\ mingyu.han@postgrad.manchester.ac.uk
}

\begin{abstract}
Globally, railway electrification is increasing at a fast rate and the overall power demand is expected to increase in the future to accommodate an increase in traffic volume and higher train speeds. However, due to dynamic train operation characteristics, the load profile at the feeder substation fluctuates and can reach beyond the transformer rating during peak timetable periods. This paper presents a multi-train simulation platform for an autotransformer feeding system using multiconductor approach. Temperature is a key factor in the operational lifetime of a transformer, influencing the rate of insulation ageing processes. Sudden load variations seen in railway systems can pose a threat to the traction transformer's lifetime. Hence, a thermal model is integrated into the simulation, with parameters considered appropriate for the transformer, in order to assess the temperature of the hottest spot within the transformer. This model links temperature to load, and, given the propensity to push more trains through old assets as electrification of transport becomes en vogue, this relationship becomes ever more important. Consideration is given to the anticipated effect of the temperature profile on a traction transformer at a substation by making use of IEC standards for power transformers with appropriate modifications to traction transformers sourced from literature.
\end{abstract}

It is found through the use of this model that traction transformers are not at high risk of thermal failure, however, some mitigation may be required against dynamic behaviour that can lead to conditions conducive to dangerous flashover events.

Keywords-Autotransformer feeding, hottest spot temperature, multi-train simulator, transformer thermal modelling

\section{INTRODUCTION}

Electrical railway systems play critical roles in modern railway transport, and the development of railway electrification is undergoing fast growth [1]. Railway powersupply systems have been intensively studied for decades. Many previous studies focused on power quality issues such as system imbalance, reactive power and harmonics [2]. In addition, considering modern trains have a maximum power up to $20 \mathrm{MW}$ with operating speed more than $300 \mathrm{~km} / \mathrm{h}$, autotransformer feeding (AT) is more generally adopted by newly-built high speed lines [1] as they can lower the current flow through the line. Some research began to look at how to manage the power flow more intelligently so as to achieve more efficient energy use. For example, authors in [3] proposed a novel co-phase feeding system to balance the load between adjacent feeding sections. The smart grid concept in railways has also been brought to attention where renewable energy sources and energy storage devices are considered potentially usable in railways [4-6]. Nevertheless, even with a smart energy management, railway transformers still endure a rapid variation of load profile. Unfortunately, their thermal performance is sometimes ignored in traction system research.

In fact, transformers generate losses while in service. Such losses generate heat, and as a result the temperature of the transformer increases: the higher the transformer loading, the higher the losses, and hence the higher the transformer temperature. Note that the relationship between load and temperature is not linear. Generally, only the hottest spot temperature (HST) of the transformer is calculated, as this dominates the behaviour within the transformer.

The transformer HST is important as it can determine the end of life through several mechanisms; some long-term (LT) and some short-term (ST). The main mechanisms to be considered are:

i. HST leads to ageing of transformer insulation through oxidation, hydrolysis and pyrolysis of insulation chemical bonds [7]. This is most prevalent at HST values above the rated transformer temperature, usually $98^{\circ} \mathrm{C}$. (LT)

ii. HST exceeding a certain value can lead to failure through formation of bubbles [8]. This usually also requires a rapid rate of temperature increase. (ST)

iii. Rapid decrease in temperature of oil may lead to gaseous bubble formation [9]. (ST)

iv. HST may rise, then fall rapidly and so also the temperature of oil, leading to formation of free water in oil [10]. (ST)

v. Temperature above flash point of oil leading to fire. (ST)

The rest of this paper is organised as follows. Section II introduces the methodologies used to build the simulation platform including the thermal model. A case study scenario is then created based on a 24-hour train timetable in Section III. Next, the results for railway thermal evaluation are shown in section IV. Discussion and conclusion are shown in Section V and VI, respectively.

\section{Methodology}

A. Symbols

$a_{\text {target }} \quad$ Target acceleration rate $\left[\mathrm{m} / \mathrm{s}^{2}\right]$

A Davis equation constant coefficient $[\mathrm{N}]$ 


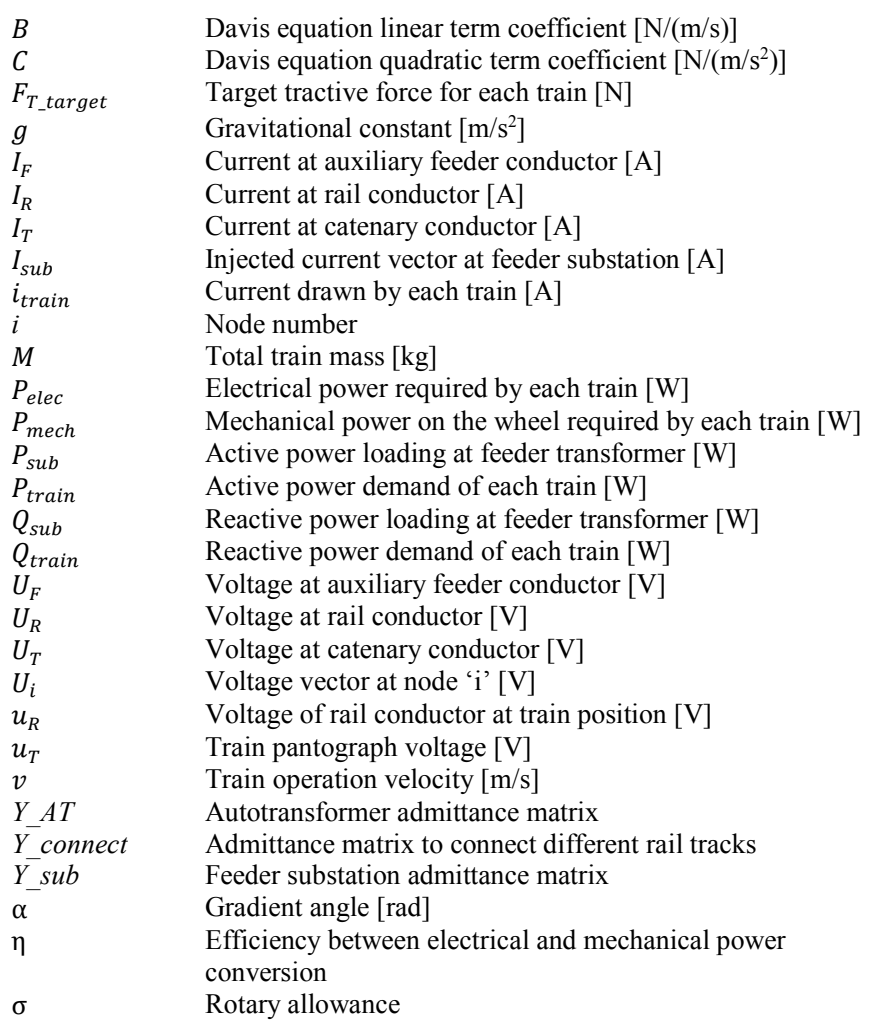

\section{B. System Overview}

Fig 1 shows an overview of the simulation platform implemented in MatLab environment. Data is first prepared and imported into three subsystems, namely Single Train Performance (STP), Electrical Network Simulation (ENS) and Transformer Thermal Simulation (TTS). For each time-step, which is set as five seconds in this study, STP calculates each train's tractive force and updates operating speed and distance. Then the simulation results are transferred to ENS where nodal analysis is applied to assess the current and voltage distribution. The substation power loading is calculated and fed into TTS. In this model, the thermal performance of traction transformer is then evaluated.

\section{Dynamic Train Movement Simulation}

A dynamic train movement simulator simulates the performance for each train. It repeatedly evaluates Newton's second law of motion based on individual train parameters to produce performance data such as speed, travelling distance and power demand. A look-up table is prepared beforehand
TABLE I. SimULATION PARAMETERS FOR Class 390 PENDOLINO [11]

\begin{tabular}{c|c}
\hline Variable & Value \\
\hline \multirow{2}{*}{ Maximum Tractive force $(\mathrm{kN})$} & $203.7(0 \leq v<24.47 \mathrm{~m} / \mathrm{s})$ \\
& $5095.2 / v(24.47 \mathrm{~m} / \mathrm{s} \leq v<62.5 \mathrm{~m} / \mathrm{s})$ \\
\hline Maximum Braking force $(\mathrm{kN})$ & 331.3 \\
\hline Maximum Speed $(\mathrm{m} / \mathrm{s})$ & 62.5 \\
\hline & $A: 5.422$ \\
Resistive Force $(\mathrm{kN})$ & $B: 0.069$ \\
& $C: 0.012$ \\
\hline Maximum Power at Rail $(\mathrm{kW})$ & 5100 \\
\hline Maximum Regenerative Power & $0(0 \leq v<9.64 \mathrm{~m} / \mathrm{s})$ \\
at Rail $(\mathrm{kW})$ & $202.74 \cdot \mathrm{v}(11.06 \leq v<30.23 \mathrm{~m} / \mathrm{s})$ \\
& $6153.66(30.23 \leq v<62.5 \mathrm{~m} / \mathrm{s})$ \\
\hline Efficiency & $85 \%$ \\
\hline
\end{tabular}

including route information and reference speed profile. At each simulation time-step, the program uses each train's current speed against the reference and calculates the required tractive force to eliminate the speed error. This simulator can be divided into the three following blocks:

\section{1) Mission Profile}

In this paper, Class 390 Pendolino Electric Multiple Unit train is used with the simulation parameters listed in Table I [11]. The pre-defined speed profile for each train is firstly generated according to the timetable and stored in an MS Excel file. The program reads the reference speed according to train location and provides the data to the speed tracking block.

\section{2) Speed Tracking Block}

Given the speed profile as a reference, a speed error is calculated by comparing the reference with actual speed. Thus a target acceleration rate $a_{\text {target }}$ is set by a proportional controller to track the reference speed, but it is limited by the maximum adhesion. The target tractive effort is calculated by using (1) and (2) [12].

$$
\begin{gathered}
F_{T_{-} \text {target }}=M(1+\sigma) a_{\text {target }}+F_{R}+M g \sin (\alpha) \\
F_{R}=A+B v+C v^{2}
\end{gathered}
$$

However, the tractive effort must conform to the maximum available tractive / braking torque of the train. The achieved tractive force $F_{T_{-} a c t u a l}$, and achieved acceleration rate $a_{\text {actual }}$ needs to be re-evaluated. Once this is obtained, train speed and distance are updated by using discrete time integration.

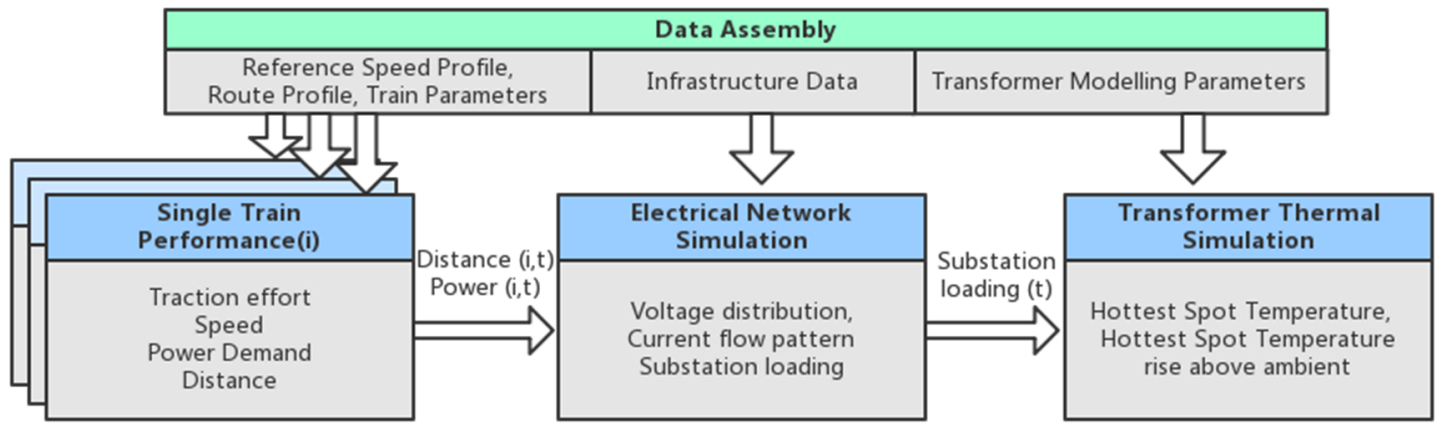

Fig 1. Overview of the simulation platform 


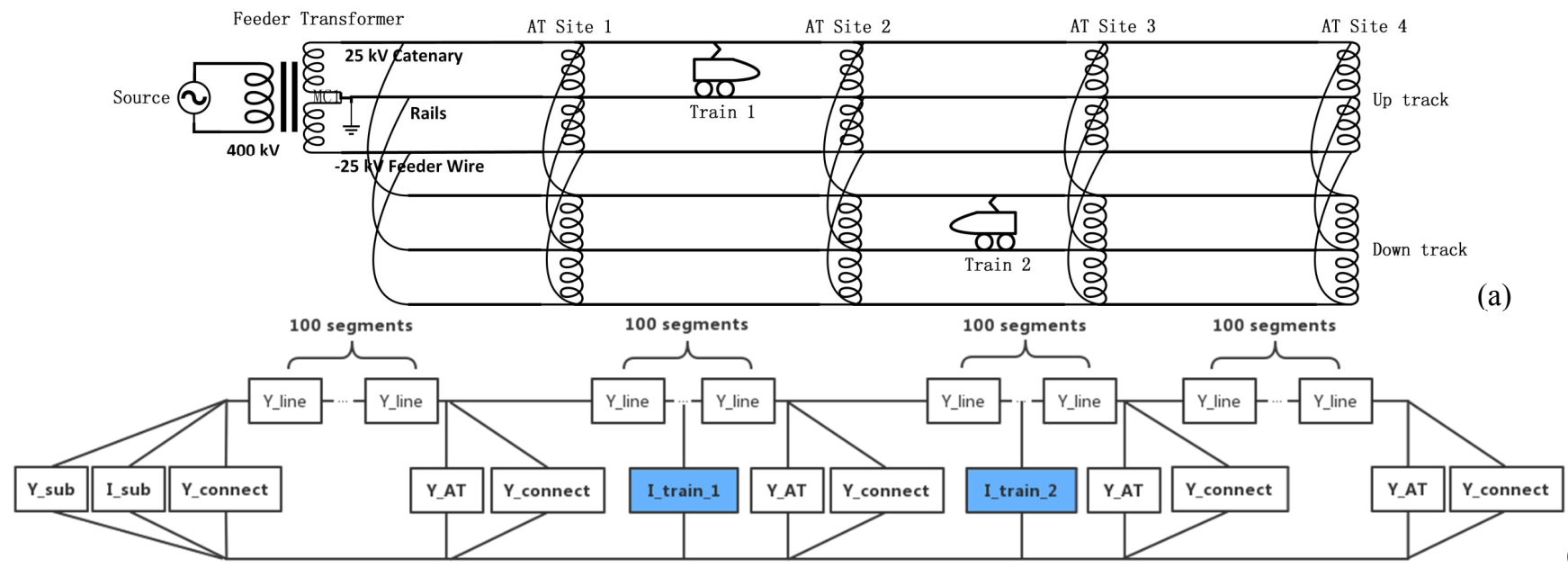

Fig 2. Schematic diagram of AT Feeding system arrangement (a) and the corresponding chain representation (b).

\section{3) Power Evaluation Block}

When $F_{T_{-} a c t u a l}$ is determined, the mechanical power demand $P_{\text {mech }}$ is calculated using (3). Hence, the electrical power demand is determined by multiplying / dividing by the efficiency, as shown in (4). The efficiency between mechanical and electrical power conversion is $85 \%$ for Class 390 . It is worth noting that the train auxiliary load is generally regarded as a relatively small and constant value compared to the train power demand, so it is not considered in this study.

$$
\begin{gathered}
P_{\text {mech }}=F_{T_{-} \text {actual }} \cdot v \\
P_{\text {elec }}=\left\{\begin{array}{cc}
P_{\text {mech }} / \eta & \text { Motoring } \\
P_{\text {mech }} \cdot \eta & \text { Regenerating }
\end{array}\right.
\end{gathered}
$$

\section{AT Feeding Network Modelling}

Fig 2 (a) shows a typical arrangement of a $40 \mathrm{~km}$ double track AT system with parallel connections. This system consists of a feeder substation and four AT sites with $10 \mathrm{~km}$ spacing. It is shown in the figure that one train is operating on the up track and the other on the down track. The modelling parameters are listed in Table II. All the network components are represented as either series or shunt connected elements. Trains are modelled as dynamic current vectors varying with power demand and location. This approach is regarded as the chain circuit topology [13] and similar approaches have also been seen in $[14,15]$.

The feeder transformer and autotransformers are modelled as admittance matrices Y_sub and Y_AT respectively, the dimensions of which depend on the number of conductors being modelled. A track circuit contains several parallel conductors such as contact wire, messenger wire, positive feeder wire $(F)$, and rails, with electromagnetic coupling effect extant across them. The formula for calculating self and mutual impedance is determined in [16]. However, it is necessary to reduce the dimension of Y_line otherwise it will be very bulky and affect the execution speed. This has been done by combining the contact wire and message wire as a catenary conductor (T). Two rails are combined to be a single conductor (R). Therefore, the overhead line system is reduced to six parallel conductors, as shown in Fig 3.

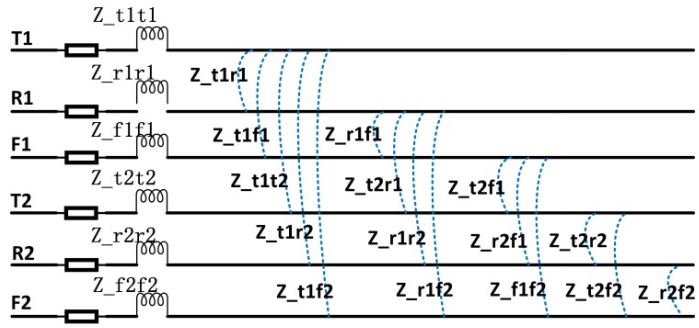

Fig 3. Schematic overview of multi-conductor feeding line model

TABLE II. PARAMETERS USED IN SIMULATION

\begin{tabular}{c|c|c}
\hline Component & Parameter & Value \\
\hline \multirow{2}{*}{ Feeder substation } & Voltage ratio (kV) & $400 / 2 \times 25$ \\
& Rated power (MVA) & 30 \\
& Short-circuit impedance (\%) & 10 \\
\hline \multirow{2}{*}{ Autotransformer } & Voltage ratio (kV) & $50 / 2 \times 25$ \\
& Rated power (MVA) & 10 \\
& Leakage impedance $(\Omega)$ & $0.1+\mathrm{j} 0.45$ \\
\hline Rail track geometry & Sourced from [13] & \\
\hline OHL electrical parameters & Sourced from [17] & \\
\hline
\end{tabular}

To simulate the dynamic movement of train loads, the railway line is split into 400 small segments with individual length of $100 \mathrm{~m}$. Hence, the total number of nodes is 401 . At each time-step, the train is modelled as a constant current vector, [I_train], using (5) and (6).

$$
\begin{gathered}
i_{\text {train }}=\left(\frac{P_{\text {train }}+j Q_{\text {train }}}{u_{T}-u_{R}}\right)^{*} \\
{\left[I_{-} \text {train }\right]=\left\{\begin{array}{c}
{\left[-i_{\text {train }}, i_{\text {train }}, 0,0,0,0\right]^{T} \text { (Up track) }} \\
{\left[0,0,0,-i_{\text {train }}, i_{\text {train }}, 0\right]^{T} \text { (Down track) }}
\end{array}\right.}
\end{gathered}
$$

Fig 2 (b) illustrates the chain representation of Fig 2 (a). $Y_{-} s u b$ and $Y_{-} A T$ are inserted into the system admittance matrix $\mathrm{Y}$ according to their position. In order to parallel connect both tracks, a shunt connected matrix $Y_{-}$connect is utilised. Besides, the power is fed from the substation node so an injected current vector $\left[I_{\text {sub }}\right]$ is calculated. $\left[I_{\text {sub }}\right]$ and [I_train] are added into the current source vector and the nodal voltages can be calculated, as shown in (7). 


$$
\left[\begin{array}{c}
U_{1} \\
U_{2} \\
U_{3} \\
\vdots \\
U_{400} \\
U_{401}
\end{array}\right]=[Y]^{-1} \cdot\left[\begin{array}{c}
I_{\text {sub }} \\
I_{-} \text {train_1 } \\
0 \\
\vdots \\
I_{-} \text {train_2 } \\
0
\end{array}\right]
$$

However, iteration is required as the train pantograph and rail voltages are unknown. The algorithm is shown in Fig 4. Firstly, the electrical parameters are imported and the system $Y$ matrix is formulated. All train power demand and location information obtained from dynamic train performance simulation is then loaded. Based on the voltage at the corresponding node, the train current is computed and the current source vector is formed. After that, nodal voltage is updated using (7). The convergence is checked, which is set as $10^{-4}$, against the error of critical node voltages compared with the previous iteration. The critical node is defined as the pantograph and rail voltage for all trains in the system. Under normal loading conditions (three trains running at maximum power on each track), no more than 6 iterations are required to reach convergence.

After obtaining node voltages, the current distribution is assessed by calculating current between each two adjacent nodes using (8).

$$
\begin{gathered}
{\left[\begin{array}{c}
I_{T 1} \\
I_{R 1} \\
I_{F 1} \\
I_{T 2} \\
I_{R 2} \\
I_{F 2}
\end{array}\right]_{i}=\left[Y_{-} \text {line }\right]^{-1} \cdot\left[\begin{array}{c}
U_{T 1} \\
U_{R 1} \\
U_{F 1} \\
U_{T 2} \\
U_{R 2} \\
U_{F 2}
\end{array}\right]_{i+1}-\left[\begin{array}{c}
U_{T 1} \\
U_{R 1} \\
U_{F 1} \\
U_{T 2} \\
U_{R 2} \\
U_{F 2}
\end{array}\right]_{i}} \\
(i=1,2,3 \ldots 400)
\end{gathered}
$$

The substation loading is evaluated by using the voltage and current values at the substation node, as in (9).

$$
\begin{array}{r}
P_{\text {sub }}+j Q_{s u b}=\left(U_{T 1}-U_{R 1}\right) \cdot I_{T 1}{ }^{*}+\left(U_{F 1}-U_{R 1}\right) \cdot I_{F 1}{ }^{*}+ \\
\left(U_{T 2}-U_{R 2}\right) \cdot I_{T 2}{ }^{*}+\left(U_{F 2}-U_{R 2}\right) \cdot I_{F 2}{ }^{*}
\end{array}
$$

The benefit of using this approach is that the node number only depends on the length of line segment so the system $Y$ matrix does not evolve with time. Only the current source vector has to be updated according the train location at each time-step. This simplifies the programing effort for multi-train simulation. Although trains can only be accommodated to fixed node positions, the accuracy is acceptable for transformer thermal performance study.

\section{E. Thermal Modelling}

Construction of the thermal model is done in accordance with IEC Standard 60076-7 [8]. This model is built by using the thermal diagram, where the hottest spot temperature within the transformer consists of three main parts: ambient temperature; top oil temperature (TOT) rise above ambient temperature; and HST rise above TOT.

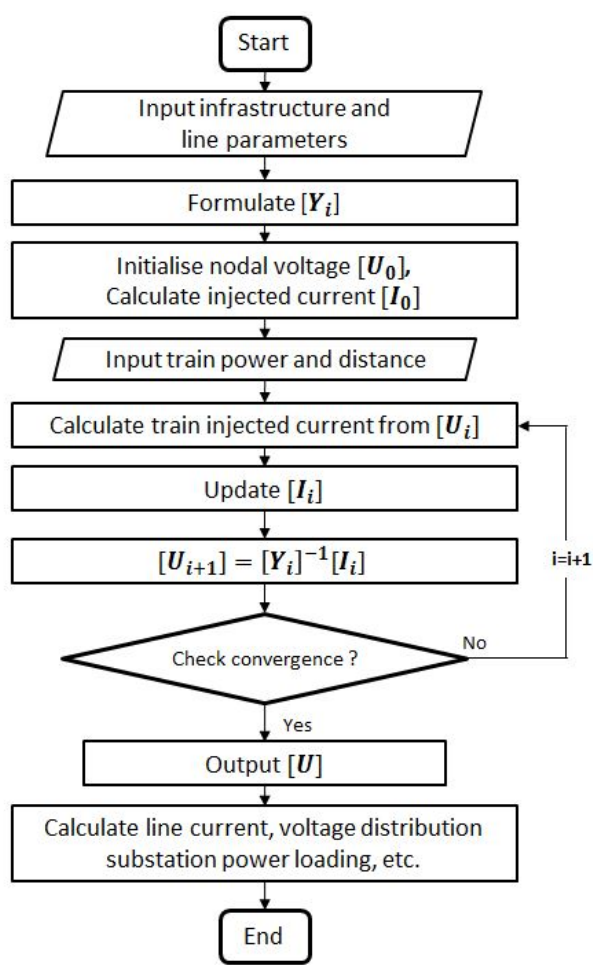

Fig 4. Flowchart of the algorithm to calculate nodal voltage

Three transformer cases are considered: two cases ('base case' and 'future case') consider the same parameters (from [8] for power transformers with all-natural cooling), however the rating of the transformer is reduced in the 'future case' from 30 MVA to 20 MVA to imitate higher loads placed on the transformer due to electrification of transport. The final case (which uses the original 30 MVA rating) is an 'alternative case' which uses different parameters suggested in [18], thereby adopting a design more suited to a transformer that experiences frequent, large, short-term peak loads.

The model's inputs are: the above-mentioned thermal parameters; the ambient temperature (which is simulated for a September day); transformer load; and transformer rating. The latter two combine in ratio to give the load factor of the transformer.

The model then outputs a HST plot, which can then be interrogated to see if the transformer is likely to be at risk of failure through any of the five mechanisms outlined in Section I. TOT is also plotted as this informs considerations relating to failure mechanisms iii, iv and $\mathrm{v}$ outlined in the introduction.

\section{CASE STUDY SCENARIO}

A case study is used to assess the thermal performance of traction transformer in the feeder substation. The feeding system used in this study is the same as the one described in Section II. There are two train stations within the feeding section. For simplicity, station A is assumed at the substation and station B is set at the furthest AT site. Gradient variation is neglected. Trains departing from station $\mathrm{A}$ to station $\mathrm{B}$ are operating on the up track while those from station $\mathrm{B}$ to station A are running on the down track. Trains accelerate when they leave the station until maximum operating speed is 


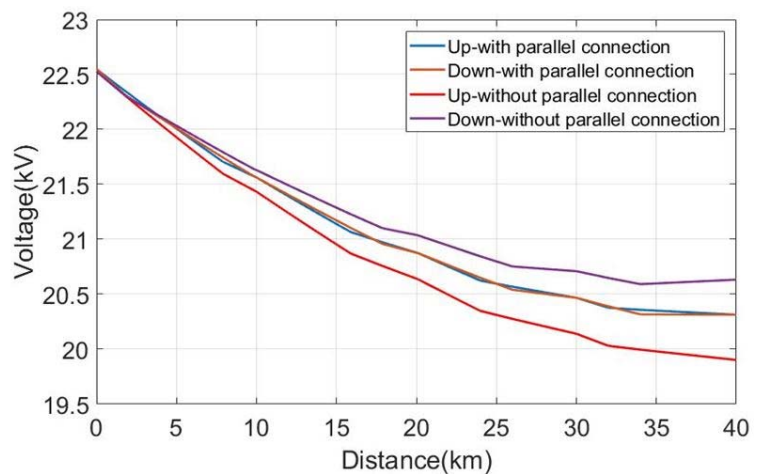

Fig 5. Line voltage distribution with 10 Class 390 trains drawing maximum power

TABLE III. DAILY TIMETABLE FOR 40 KM DOUBLE-TRACK RAILWAY LINE

\begin{tabular}{|c|c|c|c|c|}
\hline \multirow{2}{*}{ Time } & \multicolumn{2}{|c|}{ Up Track } & \multicolumn{2}{c|}{ Down Track } \\
\cline { 2 - 5 } & Number & Interval (s) & Number & Interval (s) \\
\hline $0: 00-6: 00$ & 1 & 1020 & 1 & 1020 \\
\hline $6: 00-10: 00$ & 5 & 180 & 5 & 180 \\
\hline $10: 00-11: 00$ & 4 & 240 & 3 & 360 \\
\hline $11: 00-15: 00$ & 3 & 360 & 2 & 420 \\
\hline $15: 00-16: 00$ & 3 & 360 & 4 & 240 \\
\hline $16: 00-20: 00$ & 5 & 180 & 5 & 180 \\
\hline $20: 00-21: 00$ & 2 & 420 & 3 & 360 \\
\hline $21: 00-24: 00$ & 1 & 1020 & 1 & 1020 \\
\hline
\end{tabular}

reached $(200 \mathrm{~km} / \mathrm{h})$. All trains brake to stop at the destination station. The whole journey takes about $840 \mathrm{~s}$ to complete. It is assumed that both station A and B are intermediate stations, i.e. trains will continue beyond the destination station.

A daily timetable is given in Table III. Peak hours are set from 06:00 to 10:00 and 16:00 to 20:00. During peak hours, the interval between trains is $180 \mathrm{~s}$ so the maximum number of trains on each track is five. In order to assess whether the system can cope with ten trains without having under-voltage problems, a static analysis is conducted based on the worst case scenario. It is assumed that there are ten trains all drawing maximum power simultaneously. Trains are located at $8 \mathrm{~km}$, $16 \mathrm{~km}, 24 \mathrm{~km}, 36 \mathrm{~km}$ and $40 \mathrm{~km}$ on up track and at $2 \mathrm{~km}$, $10 \mathrm{~km}, 18 \mathrm{~km}, 26 \mathrm{~km}$ and $34 \mathrm{~km}$ on down track, with reference to the substation. The voltage distribution is shown in Fig 5. It shows that for parallel connected double-track system, the minimum voltage for up track and down track are both $20.3 \mathrm{kV}$, occurring at the furthest AT site. A comparison has been made by looking at voltage distribution without parallel connection. It can be seen the lowest voltage in the system is $19.9 \mathrm{kV}$ at the furthest AT site. This confirms that parallel connected topology is able to withstand heavier loading conditions. The minimum voltage does not fall below the minimum allowable voltage $(19.0 \mathrm{kV})$ [19], even in the worst case scenario. As a result, voltage dependent train operation is not seen in this study.

\section{RESULTS ANALYSIS}

According to the timetable shown in Table II, a substation loading profile is obtained as shown in Fig 6. This load profile is assessed on a fineness of five seconds, and has the HST plot shown in Fig 7. These values are based on the ambient temperature of a September day, and so are not 'worst case', but are generally representative. Fig 7 also shows the TOT.

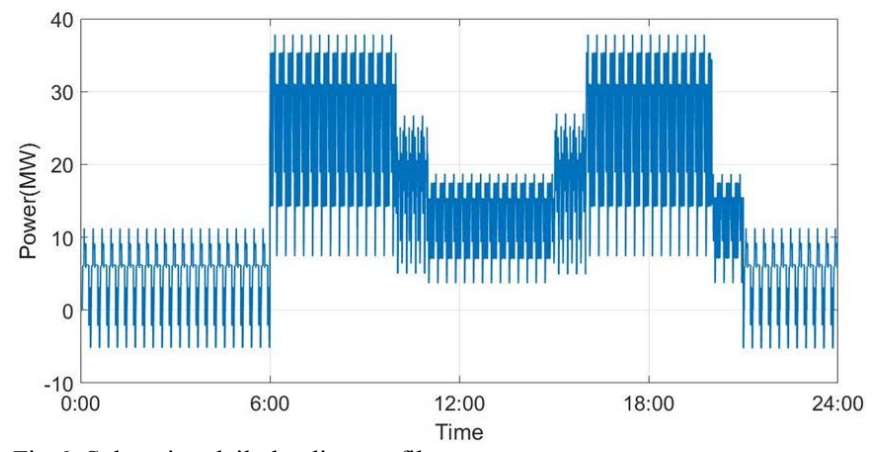

Fig 6. Substation daily loading profile

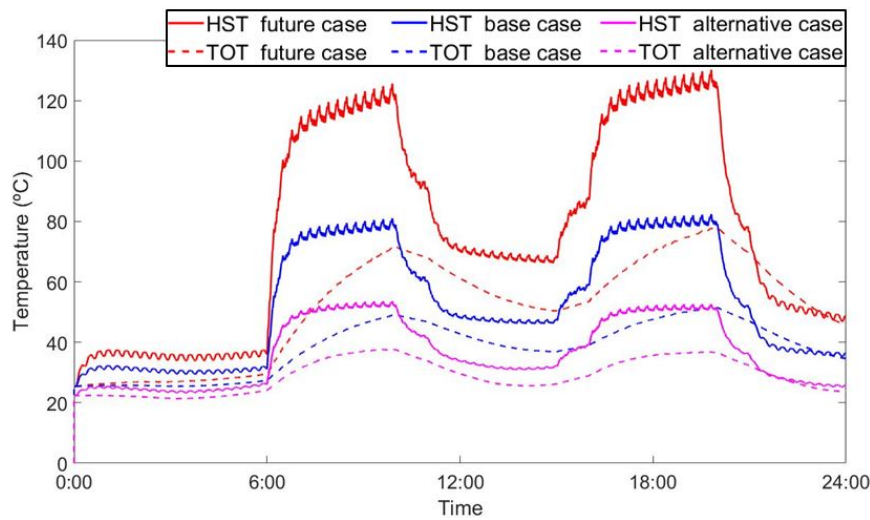

Fig 7. Traction transformer thermal performance evaluation

It is seen that there are two strong peaks in HST which coincide with the peak loading times (peak hours). The HST rises rapidly to a peak value during this period, before falling rapidly to a considerably lower value in the off-peak periods.

In the base case, maximum temperatures seen are far below the rated operating temperature of $98{ }^{\circ} \mathrm{C}$. The rate of temperature increase is largest at just after 06:00 with a value of $3.1 \mathrm{~K} / \mathrm{min}$, and the rate of temperature decrease is greatest just after 10:00, at $2.1 \mathrm{~K} / \mathrm{min}$. This implies that the swift change from off-peak, to peak, and back again could be the main intervals where the transformer is placed at risk. For the alternative case, maximum temperatures and changes of temperature are seen to be much lower; for the future case, which considers additional loading, temperatures can be dangerously high (Fig. 7).

\section{DISCUSSION}

From the results of this modelling, there are several key areas of interest. All of these relate to the effect of temperature on the transformer lifetime, and specifically its propensity to fail under the loading conditions simulated. The output HST profile shown in Fig 7 suggests that the temperature is always significantly below the rated temperature of $98{ }^{\circ} \mathrm{C}$. This is encouraging, as it suggests that transformer ageing will be below the designed for rate, and hence the transformer is unlikely to reach its useful end of life early.

Transformer ageing addresses long term concerns, yet short term failure of transformers can occur as identified in Section I. The absolute HST seen in the transformer here is not high enough to make bubble formation a concern, despite high rates of temperature increase. 


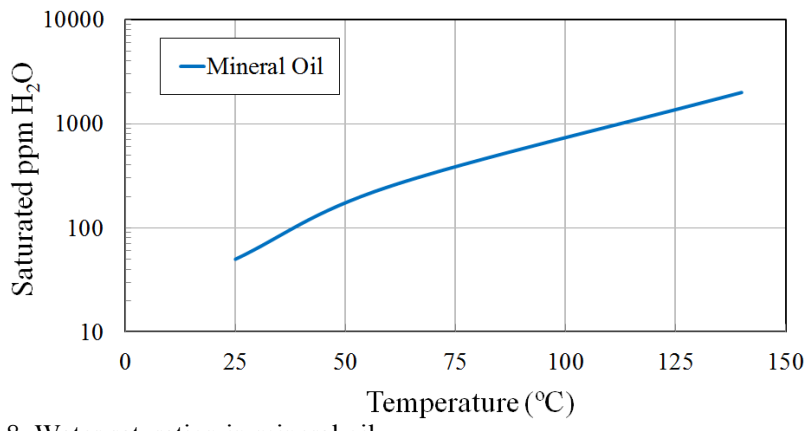

Fig 8. Water saturation in mineral oil

In this study, it can be seen that, especially during the 'future case', there are two occasions of prolonged rapid temperature reductions in the transformer, from relatively high temperatures to much lower temperatures. Fig 7 shows how the TOT tracks the HST, and from this it can be concluded that formation of free water could be of concern - especially when viewed in collaboration with Fig 8 which indicates the amount of water that oil can hold at saturation at difference temperatures (shown for mineral oil). Using the temperatures of the high $\left(77^{\circ} \mathrm{C}\right)$ and low $\left(45^{\circ} \mathrm{C}\right)$ points in Fig 8, the difference in saturation is approximately $500 \mathrm{ppm}$. For transformers that have operated for a period of time and have hence become wetter, this may be a concern. Similarly, some consideration must be given here to gaseous generation through the same mechanism of rapid temperature reduction. Dissolved nitrogen (among other gases) will tend to be released from the oil as oil temperature decreases (as the transformer volume occupied by the oil is reduced due to a reduction of its density). In the same fashion as with water, when the rate of this temperature reduction is rapid, the gases may release as bubbles and this can endanger the transformer.

\section{CONCLUSION}

Concerns about increasing railway traffic volume and power demands lead to the preference of AT feeding system. Although traction transformers are designed to operate at greater than normal loading conditions, they are under pressure from extreme loading conditions during peak hours. Therefore, a thermal assessment is necessary to address potential hazard to transformers. The results of this study show that traction transformers are at relatively low risk of thermal failures, but should be monitored to protect against potential free water formation which can lead to instantaneous failure due to flashover. Further, the potential for high instantaneous HST could be serious if additional loading of these transformers occurs.

This type of study has not been paid enough attention in traction systems. In this paper, an AT feeding simulation platform with integrated thermal modelling has been built in MatLab to meet this requirement. Future study will focus on improving the veracity of the model and include specific route analysis.

\section{ACKNOWLEDGMENT}

The authors acknowledge financial support from EPSRC (EP/L016141/1) through the Power Networks Centre for Doctoral Training.

\section{REFERENCES}

[1] R. D. White, "AC $25 \mathrm{kV} 50 \mathrm{~Hz}$ electrification supply design," presented at the Railway Electrification Infrastructure and Systems (REIS 2011), 5th IET Professional Development Course on, 2011.

[2] S. M. Mousavi Gazafrudi, A. Tabakhpour Langerudy, E. F. Fuchs, and K. Al-Haddad, "Power Quality Issues in Railway Electrification: A Comprehensive Perspective," IEEE Transactions on Industrial Electronics, vol. 62, pp. 3081-3090, 2015.

[3] Z. Shu, S. Xie, and Q. Li, "Development and implementation of a prototype for co-phase traction power supply system," in Power and Energy Engineering Conference (APPEEC), 2010 Asia-Pacific, 2010, pp. 1-4.

[4] J. Aguado, A. J. Sanchez-Racero, and S. de la Torre, "Optimal Operation of Electric Railways with Renewable Energy and Electric Storage Systems," IEEE Transactions on Smart Grid, 2016.

[5] P. Pankovits, J. Pouget, B. Robyns, F. Delhaye, and S. Brisset, "Towards railway-smartgrid: Energy management optimization for hybrid railway power substations," in Innovative Smart Grid Technologies Conference Europe (ISGT-Europe), 2014 IEEE PES, 2014, pp. 1-6.

[6] E. P. de la Fuente, S. K. Mazumder, and I. G. Franco, "Railway Electrical Smart Grids: An introduction to next-generation railway power systems and their operation," IEEE Electrification Magazine, vol. 2, pp. 49-55, 2014.

[7] M. J. Heathcote, J\&P Transformer Handbook, 13th ed.: Elsevier Ltd., 2007.

[8] BS IEC 60076- 7:2005 2010. "Power transformers. Loading guide for oil-immersed power transformers,"

[9] W. McNutt, T. Rouse, and G. Kaufmann, "Mathematical modelling of bubble evolution in transformers," IEEE transactions on power apparatus and systems, pp. 477-487, 1985.

[10] V. Aralkellian and I. Fofana, "Water in oil-filled, high-voltage equipment, Part I: States, solubility, and equilibrium in insulating materials," IEEE Electrical Insulation Magazine, vol. 23, pp. 15-27, 2007.

[11] N. Zhao, "Railway traffic flow optimisation with differing control systems," Ph.D. dissertation, University of Birmingham, 2013.

[12] F. Schmid and C. J. Goodman, "Electric railway systems in common use," presented at the 5th IET Professional Development Course on Railway Electrification Infrastructure and Systems (REIS 2011) 2011.

[13] W. Mingli, C. Roberts, and S. Hillmansen, "Modelling of AC feeding systems of electric railways based on a uniform multi-conductor chain circuit topology," 2010.

[14] Y. Chen, R. White, T. Fella, S. Hillmansen, and P. Weston, "Multiconductor model for AC railway train simulation," IET Electrical Systems in Transportation, vol. 6, pp. 67-75, 2016.

[15] Z. Tian, S. Hillmansen, C. Roberts, P. Weston, N. Zhao, L. Chen, et al., "Energy evaluation of the power network of a DC railway system with regenerating trains," IET Electrical Systems in Transportation, vol. 6, pp. 41-49, 2016.

[16] NR /GN/ELP/27312: 2006. "Impedances of $25 \mathrm{kV}$ a.c. overhead lins for Classic system,".

[17] Z. Liu, G. Zhang, and Y. Liao, "Stability Research of High-Speed Railway EMUs and Traction Network Cascade System Considering Impedance Matching," IEEE Transactions on Industry Applications, vol. 52, pp. 4315-4326, 2016.

[18] L. Wang, L. Zhou, H. Tang, D. Wang, and Y. Cui, "Numerical and experimental validation of variation of power transformers' thermal time constants with load factor," Applied Thermal Engineering, vol. 126, pp. 939-948, 2017.

[19] BS EN 50163. "Railway Applications, Supply voltages of traction systems," 